\title{
Generation of Photovoltaic Solar Energy. Evaluation of the Demand Curve with the Insert of Grid-connected Photovoltaic Power System at CINDACTA II, Curitiba-PR, Brazil.
}

\author{
Rosiane Bonatti Ribeiro ${ }^{1 *}$, Ramon Bulhões e Silva ${ }^{2}$, Rodrigo Luiz Frigotto ${ }^{3}$, Jair \\ Urbanetz Junior ${ }^{1,4}$ \\ ${ }^{1}$ Programa de Pós-Graduação em Engenharia Civil, Universidade Tecnológica Federal do Paraná, \\ Curitiba, Brasil; ${ }^{2}$ Centro Integrado de Defesa Aérea e Controle de Tráfego Aéreo II, Curitiba, Brasil, ${ }^{3}$ \\ Programa de Pós-Graduação em Engenharia Elétrica e Informática Industrial, Universidade \\ Tecnológica Federal do Paraná, Curitiba, Brasil; ${ }^{4}$ Programa de Pós-Graduação em Sistemas de \\ Energia, Universidade Federal Tecnológica do Paraná, Curitiba, Brasil.
}

\begin{abstract}
Unlike some countries, Brazil has a predominantly hydraulic energy matrix, a clean and renewable source. But, in recent years, both the non-renewal of the normal volumes of water in the reservoirs and the lack of consciousness in the consumption of water and energy have placed the country in a critical state of energy supply leading to many intensive policies to reduce its consumption. In contrast, energy from Photovoltaic (PV) on-Grid Systems has grown dramatically in recent years. In this sense, this study presents an analysis of the contribution of the energy generated by a PV on-Grid Systems to be installed in CINDACTA II, in order to make re-contracting a lower demand possible and also reduce electric energy consumption and its cost.
\end{abstract}

Key words: Photovoltaic System, Demand, Renewable Energy, Save Energy

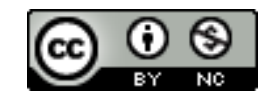

*Author for correspondence: rosianeb@gmail.com 


\section{INTRODUCTION}

With the development of the world economy, the demand for electric energy is increasing on a daily basis. To meet this demand, new sources of electricity are being built, and prioritizing renewable sources, that respect living beings and their environment and reduce the emission of greenhouse gases (GHG), has shown to be a challenge ${ }^{4}$. On the other hand, the production of energy through renewable sources has been stimulated, increasing its participation in the global energy matrix ${ }^{8}$. Brazil, for years, has stood out worldwide in the energy participation of renewable sources in its electrical matrix, representing $75.5 \%$ of the total ${ }^{4}$.

Good practices and conscious use of electric energy should be encouraged in society together with investment in energy efficiency and energy generation in a sustainable manner. It is noteworthy that public agencies play an essential role as disseminators of culture of rational uses of our energy resources, since their actions are seen as a model by society.

The implementation of PV on-Grid Systems, including urban centers, has made the distributed generation of electric energy possible and has also been promoting and encouraging sustainable actions ${ }^{8}$. In 2015, distributed generation produced $34.9 \mathrm{GWh}$ with an installed capacity of $16.5 \mathrm{MW}$, with solar Photovoltaic (PV) production totaling 20.0 GWh and 13.3 MW of installed capacity ${ }^{4}$.

Photovoltaic systems connected to the grid are regulated in Brazil by Resolution 482/2012 of the National Electric Energy Agency (ANEEL), as well as the forms of energy compensation and incident taxes. As a form of incentive, the National Council of Treasury Policy, through Agreement $N^{\circ} 16 / 2015$, authorized the exemption of tax on electric energy circulation operations, which deals with the aforementioned Resolution of states that have signed the agreement.

By 2014, concerning photovoltaic energy, Germany was the country with the highest installed capacity, being surpassed in 2015 by China and in 2016 by Japan. Currently, China has about $77 \mathrm{GW}$ installed, adding only in 2016, almost equivalent to the total installed in Germany, as can be seen in Figure 1. It should be considered, in this context, that the energy matrix of China and Japan is predominantly coal, a source of non-renewable energy ${ }^{6}$. Brazil has an installed capacity of PV energy of $21 \mathrm{MW}$, but its energy matrix is predominantly hydraulic, a clean and renewable source ${ }^{4}$. In a more regional scenario, it is estimated that Paraná has an approximate superiority of 59\% in relation to Germany in relation to the average annual productivity of photovoltaic energy in the inclined plane 9 .

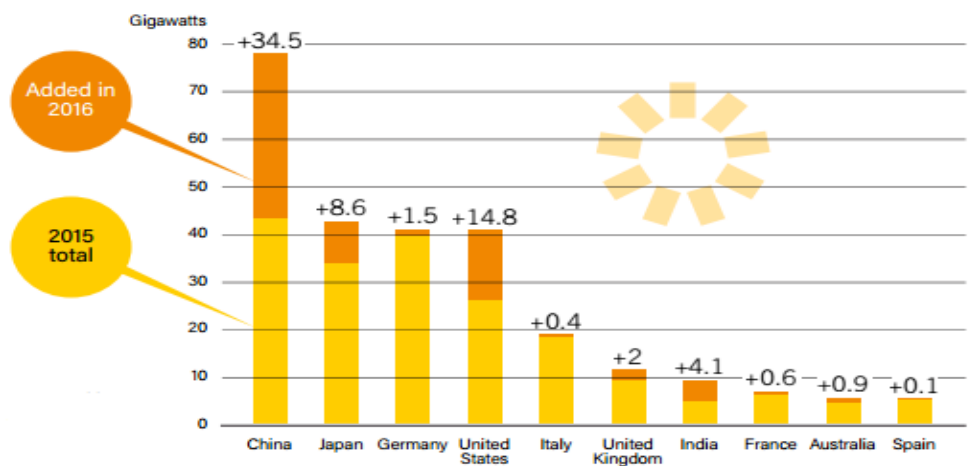

Figure 1- Photovoltaic Solar Capacity installed and added Source: REN 21

In the context of the Brazilian Air Force, the Second Integrated Center for Air Defense and Air Traffic Control (CINDACTA II), located in Curitiba, Paraná, Brazil, responsible for controlling and coordinating airspace in the southernmost region of Brazil, uses diverse electronic equipment for the adequate monitoring and 
communication with the aircraft. Such equipment sets have considerable energy consumption, maintaining a high daily demand, as they operate 24 uninterrupted hours per day, all year round. Actions to save energy have been sought to, along with other sustainable actions, contribute to the maintenance of natural resources.

\section{METHOD}

Solar radiation data from the place where the PV system is to be installed is of paramount importance in its feasibility study. There are two types of this system, the Photovoltaic (PV) off-Grid System and the Photovoltaic (PV) on-Grid System that can be used in buildings. However, it is emphasized that, if the site is serviced by an electric utility, due to the absence of batteries in the PV on-Grid Systems, all the energy produced by the modules is used, thus giving it high productivity ${ }^{10}$.

The data of solar irradiation for the accomplishment of this study were taken from the Brazilian Atlas of Solar Energy, and are made available in spreadsheets with intercompared data in points that are not more than $10 \mathrm{~km}$ apart. These data are collected by sensors at the stations of the SONDA (National Organization of Environmental Data) network, arranged at specific points in Brazil and made available for public consultation hourly on the INMET website (National Institute of Meteorology $)^{2}$.

For the studies and parameterizations, it was defined that, in order to identify the worst and the best energy production scenarios, the days with the lowest and highest solar irradiation should be identified in the period between July 1, 2016 and June 30, 2017. Furthermore, to allow the evaluation of the decrease of the peak of demand, these days should also coincide with days of full unit work (CINDACTA II).

With the Hemera CAS telemetry platform ${ }^{7}$, made available by the local Power utility (COPEL) for Group A (high voltage) customers, it is possible to obtain some information through the electric energy meter with its mass memory. With the consumer's profile, it is possible to obtain the information of consumption, monthly invoicing and necessary demand for the evaluation.

Among the available areas within the unit, for the implementation of the PV on-Grid Systems, the roofs (with their respective azimuthal deviations) and those free of buildings were evaluated. It was evaluated that the best option is a site with an area of more than $20,000 \mathrm{~m}^{2}$, free of buildings, which provides the correct positioning of the modules with the best orientation and slope, thus favoring the maximum annual power generation. In this way there is no deviation in the positioning of the modules and there is no need to recalculate the irradiation, otherwise the RADIASOL software would be used.

According to paragraph 1 of article 4 of Normative Resolution $N^{\circ} 482 / 2012$, the power of the PV on-Grid Systems to be installed can have the maximum contracted demand, which in the case of CINDACTA II is $950 \mathrm{~kW}$.

To start the calculations of the photovoltaic system, it is necessary to know some data such as daily, monthly or annual energy consumption average, the percentage to be supplied from this amount and also the demand throughout the day. The area for installation of the system is one of the limiting factors of the design, it defines the quantity of modules that fits in the premise and is defined by equation $1^{11}$.

Nmod $=\frac{\mathrm{A} \text { av }}{\mathrm{A} \text { mod }}$

Where:

Nmod: Module number (unit);

A av: area available $\left(\mathrm{m}^{2}\right)$;

A mod: Module area plus the shading area of the module $\left(\mathrm{m}^{2}\right)$. 
In order to calculate the peak power of the PV Panel, the number of modules and the peak power of each module are required, according to equation $2^{11}$.

$P p v=\operatorname{Pmod} x$ Nmod

Where:

Ppv: peak power of the photovoltaic panel $(\mathrm{kWp})$;

Pmod: Module power (kWp);

Nmod: Module number (unit).

In order to calculate the energy generated by the panel during the year, the typical day irradiation data of each month can be used. It can be taken directly from the spreadsheet to the Inclined Plan of the Brazilian Atlas of Solar Energy, to the nearest point to the panel area, since the modules will be installed in order to favor the average annual generation. Equation $3^{11}$ is used to calculate the generated energy.

$E=\frac{\mathrm{Ppv} X \text { Htot X PR }}{\mathrm{G}}$

Where:

E: average daily electricity $(\mathrm{Wh} / \mathrm{dia})$;

Ppv: peak power of the photovoltaic panel (Wp);

Htot: monthly average daily solar irradiance for the defined site $\left(\mathrm{Wh} / \mathrm{m}^{2}\right.$. dia);

PR: Performance Ratio (betwen 0,70 and 0,80 - used 0,75 to this study);

G: irradiance in the Standard Test Conditions (STC) $\left(1.000 \mathrm{~W} / \mathrm{m}^{2}\right)$.

Rounding off the analysis, it is necessary to calculate the power generated by the panel during the day, considering the hourly irradiance data taken from the National Institute of Meteorology (INMET) website and then compare it with the daily demand curve to verify the contribution of the PV on-Grid Systems.

\section{RESULTS AND DISCUSSIONS}

From the latitude and longitude of the PV on-Grid Systems, the monthly average daily irradiance values are identified in the worksheet for the Inclined Plane of the Brazilian Atlas of Solar Energy for the point closest to the place where the installation of the photovoltaic system was studied (lat: $-25.43 \mathrm{~S}$, long: $-49.27 \mathrm{~W}$ ):

Table 1- Radiation on the Inclined Plane to the point (Wh)

Jan Feb Mar Apr May Jun Jul Aug Sep Oct Nov Dec

$\begin{array}{llllll}5.19 & 5.325 .574 .954 .54 & 4.52 & 4.225 .394 .974 .95 & 5.395 .18\end{array}$

Annual Total: 5.01

Source: The author

For this system, a PV module has been predefined that meets the requirements of Brazilian standard NBR 11876: 2010 - Photovoltaic Modules, which also complies with National Metrology Institute (INMETRO) standards. In this way, the module to be used in the studies will be of the Canadian Solar brand, with nominal power of 330 $\mathrm{Wp}$, useful area of $1.94 \mathrm{~m}^{2}$. For the purpose of calculation of area occupation by the modules, without shading one another, separations gaps were calculated between them in order to avoid the shadows. This resulted in an additional area of $1.70 \mathrm{~m}^{2}$ per module to be considered in the calculation of the number of panel modules ${ }^{4}$.

As the available area is $20,000 \mathrm{~m}^{2}$, half of it will be used with the placement of modules. Thus, using the equation 1, the number of modules of the system is calculated:

$$
\begin{aligned}
& N \bmod =\frac{\mathrm{A} \mathrm{av}}{\mathrm{Amod}} \\
& N \bmod =\frac{10.000}{(1,94+1,70)} \quad \sim 2.700 \text { units }
\end{aligned}
$$


Knowing the number of modules and their specifications, it is possible to calculate the peak power of the PV Panel, according to equation 2:

$P p v=P \bmod x$ Nmod

$P p v=330 \times 2.700=891 \mathrm{kWp}$

It can be noticed that with the use of half of the area studied, the power of the panel was close to the demand contracted, as recommended in Normative Resolution 482/2012, making it unfeasible to increase. For this type of setup, the regulatory standard is NBR 16274: 2014 - Photovoltaic systems connected to the grid. Also, the system must meet module 3 of PRODIST (Procedure of Distribution of Electric Power in the National Electrical System), which is ANEEL's procedure that aims to establish conditions of access (connection and use) for new or existing accessors.

Table 2 presents, according to the analyzed period (July $1^{\text {st }}, 2016$ to June $30^{\text {th }}, 2017$ ): a) the consumption of the institution in monthly terms; b) the energy generated by the photovoltaic system, according to equation 3, given the peak power of the PV Panel (Ppv), the average monthly solar irradiance (Htot) from the Inclined Plane worksheet, the Brazilian Solar Energy Atlas, the System Performance Rate (PR), estimated at 0.75, and the irradiance at the normal conditions of temperature and pressure; c) the energy savings in percentage according to the month; and d) annual totals.

$E=\frac{\text { Ppv X Htot X PR }}{G}$

Table 2- Consumption, Power Generation and Energy Savings

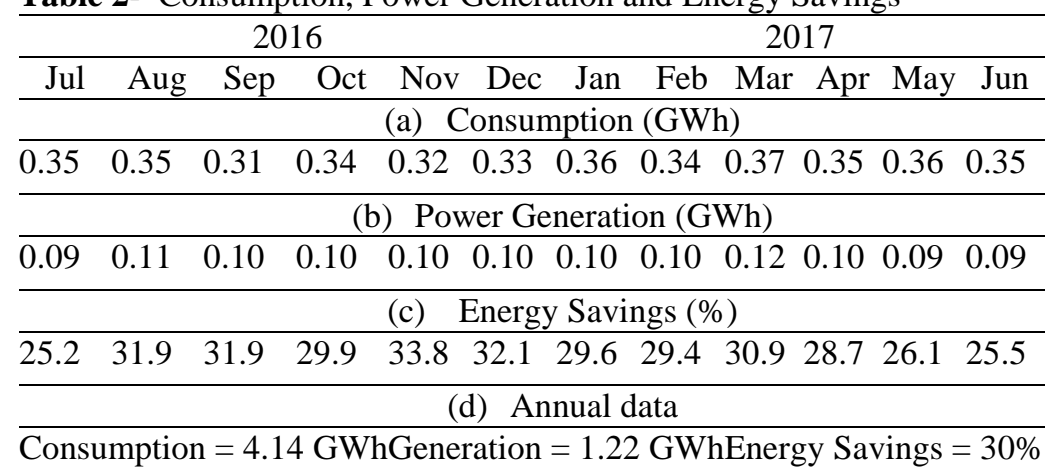

Source: The author

However, in order to calculate the performance of the panel throughout the day and then analyze it together with the unit demand graph, hourly data for each coordinate is needed. Since the Atlas data do not display hourly values for each coordinate, it is necessary to search for such information on the site of INMET, in the automatic stations, in particular the one of Curitiba. It is located on the Campus of the Federal University of Paraná (UFPR) and is less than $40 \mathrm{~km}$ from the PV on-Grid Systems location, so it is perfectly applicable for the study of the data.

With the evaluation of the daily irradiation in the period of July $1^{\text {st }}, 2016$ to June $30^{\text {th }}$, 2017, it was possible to identify the days of lowest and highest irradiation, being August $18^{\text {th }}, 2016$ and December $05^{\text {th }}, 2016$ respectively.

With the data of Solar Radiation taken from the INMET website for August $18^{\text {th }}$, 2016, the day of lowest irradiation in the evaluated period, the Solar Irradiation chart was set up, which is presented in Figure 2. It presented a maximum value of $0.11 \mathrm{kWh}$ $/ \mathrm{m}^{2}$ at 2:00 $\mathrm{pm}$ and $0.69 \mathrm{kWh} / \mathrm{m}^{2}$ accumulated on the day. 


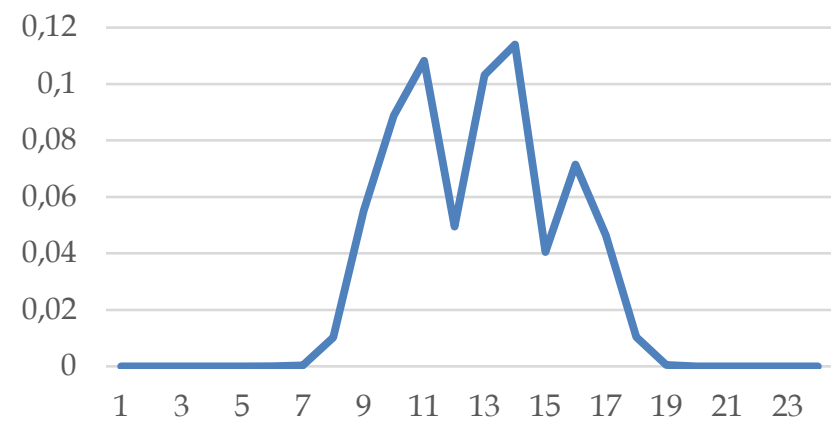

Figure 2- Solar Irradiation of August $18^{\text {th }}, 2016\left(\mathrm{kWh} / \mathrm{m}^{2}\right)$

Source: The author

Figure 3 shows the unit's demand graph (CINDACTA II) for the day of lowest irradiance, obtained from the CAS Hemera platform of COPEL 7 .

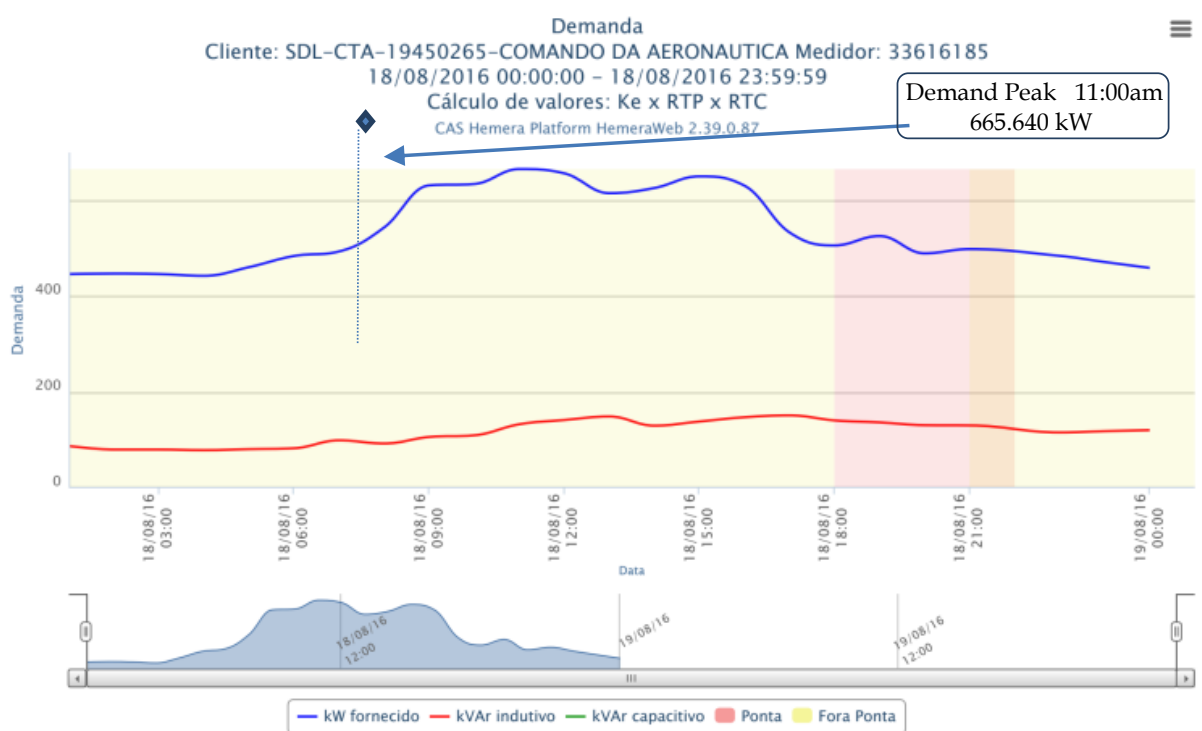

Figure 3- Demand of August 18 ${ }^{\text {th }}, 2016(\mathrm{~kW})$

Source: CAS Hemera

Due to the use of non-stop electronic equipment for air defense and air traffic control, it can be verified in the demand curve that the demand value at no time of the day is less than $400 \mathrm{~kW}$. With the beginning of the administrative shift at 8:00 am, demand increases and, as there is a restaurant inside the institution to serve all the employees (some of the cooking and preparation equipment are electric), demand usually peaks at 11:00 am at $665.640 \mathrm{~kW}$. The demand falls as the employees leave the administrative sections for the lunch break, rising again on their return, with the activation of computers and use of air conditioning. The administrative shift ends at 4:00 pm, while the security and operational activities of monitoring and control remain active.

Figure 4 shows the power delivered by the photovoltaic system on this day, totaling $466.86 \mathrm{kWh}$, with a peak of $76.18 \mathrm{kWh}$, at 2:00 pm. 


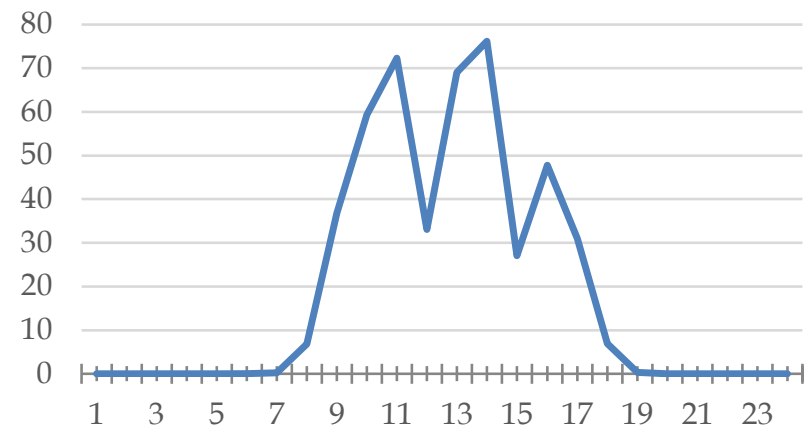

Figure 4- Power of the System - August $18^{\text {th }}, 2016(\mathrm{~kW})$ Source: The author

Figure 5 shows the overlap of the demand graphs, in the current configuration in blue, without the PV on-Grid Systems and how the graph would appear in red if the system were in operation. It is shown that the system contributes to the reduction of the energy consumption from the utility during the day, but there is no excess energy generation on this day.

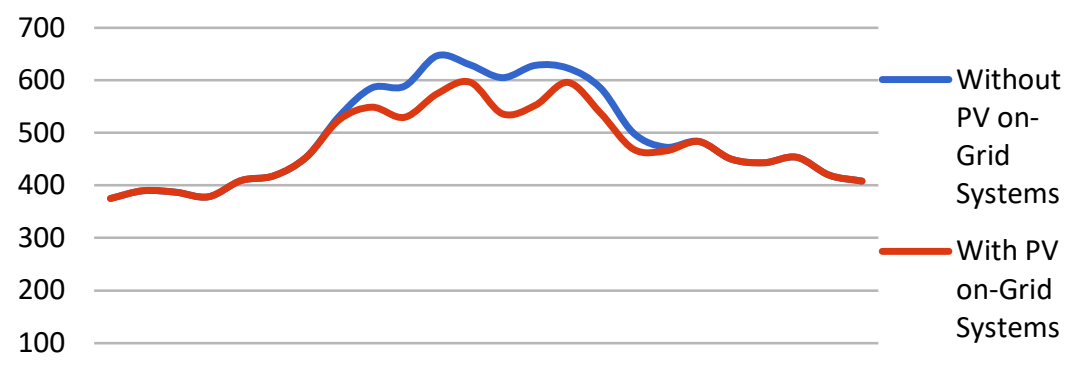

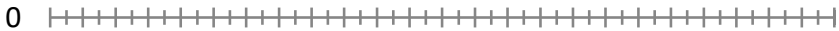

1233456789101112131415161718192021222324

Figure 5- Demand without and with SFVCR- Aug 18, $2016(\mathrm{~kW})$

Source: The author

For December $5^{\text {th }}, 2016$, day of maximum daily irradiation in the evaluated period, the graph presented in Figure 6 was elaborated. The day presented a maximum irradiation of $1.13 \mathrm{kWh} / \mathrm{m}^{2}$ at $1: 00 \mathrm{pm}$ and $8.98 \mathrm{kWh} / \mathrm{m}^{2}$ accumulated on the day.

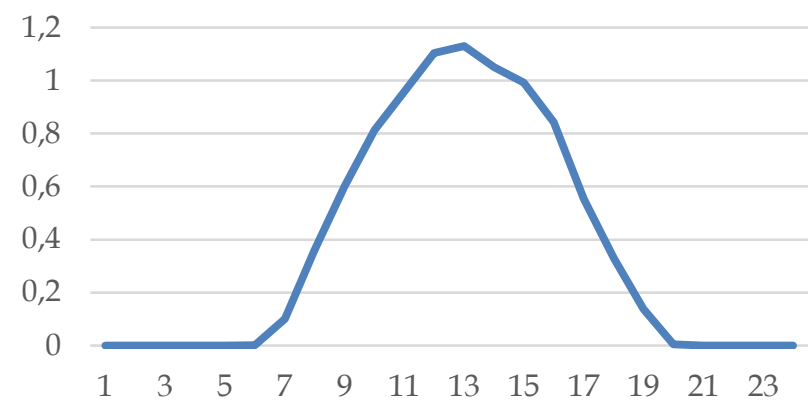

Figure 6 - Solar irradiation of Dec 05, $2016\left(\mathrm{kWh} / \mathrm{m}^{2}\right)$

Source: The author

For the collection of the demand data, the CAS Hemera platform of $\mathrm{COPEL}^{7}$ was used. Figure 7 shows the demand graph. It its shown that the curves of demand, both on the day of lowest and greatest irradiation have a similar configuration, which 
implies that climate and temperature do not directly influence the demand of the institution. The peak hour was identified as being at 10 am with a value of 574.200 $\mathrm{kW}$. The peak occurred in different time and reached a smaller value when compared to the demand of August $18^{\text {th }}, 2016$, shown in Figure 3, which reflects a seasonal behavior of the server. In December, there are usually fewer hours in the administrative shift and a relevant share of employees go on summer vacation

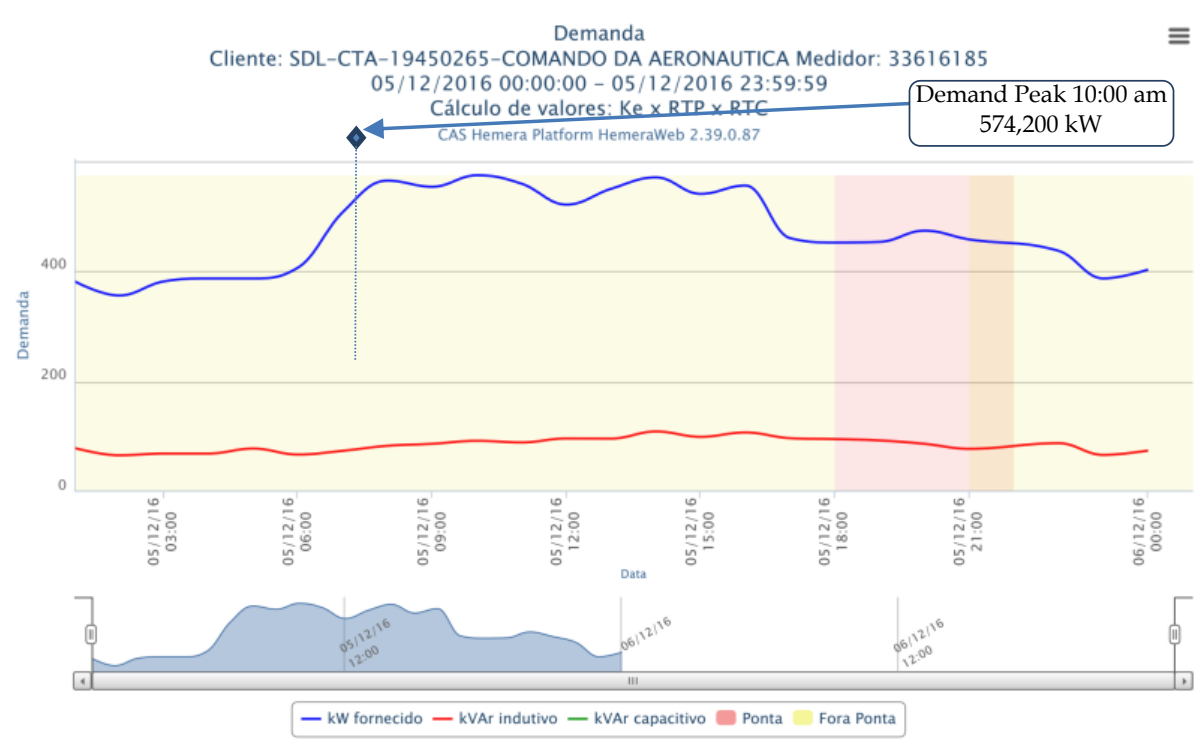

Figure 7- Demand on December $5^{\text {th }}, 2016(\mathrm{~kW})$ Source: CAS Hemera

The configuration of the power graph delivered by the system throughout the day is shown in Figure 8, totaling 6,019.27 kWh, with a peak of $755.308 \mathrm{kWh}$ at $1 \mathrm{pm}$.

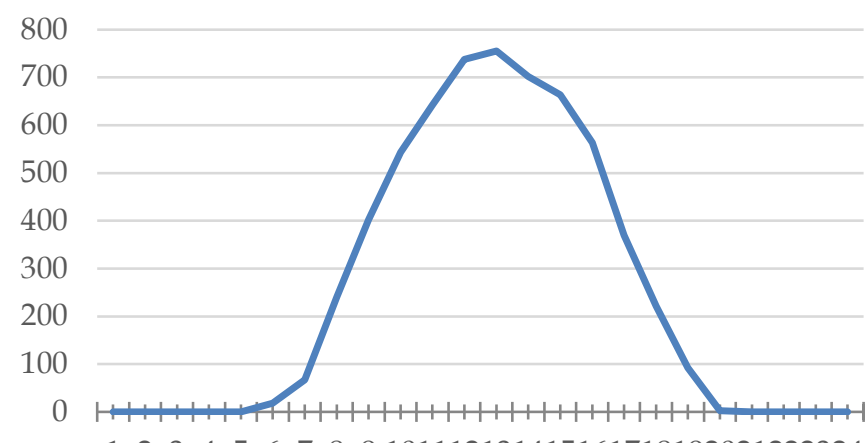

123456789101112131415161718192021222324

Figure 8 - System Power - December 5 ${ }^{\text {th }}, 2016(\mathrm{~kW})$

Source: The author

Figure 9 shows the overlap of the demand graphs, in the current configuration in blue, without the PV on-Grid Systems; and, in red, how the graph would appear if the system were in operation. It is identified that between 10:00 am and 4:00 pm the system delivers more power than it is demanded by the load, at which time the generated energy would be surplus, generating credits for compensation. Also, it can be seen that the peak demand changed from 10:00 am to 08:00 pm. 


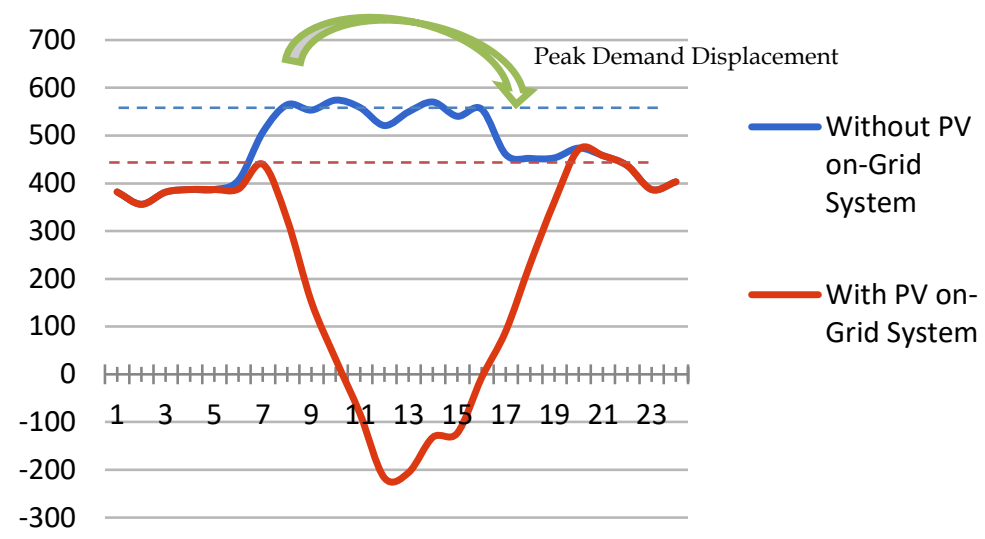

Figure 9- Demand with and without PV on-Grid-System - 05/12/2016 (kW)

Source: The author

\section{CONCLUSION}

Analyzing the graphs presented, especially the graph that shows the overlapping of the demand curve with and without the PV on-Grid Systems, it is possible to conclude that, with the insertion of the system, there is a significant reduction in energy consumption by around 30\%. Savings take place both on days of low or high solar irradiation. and the use of this type of energy generation from a sustainable source contributes to the reduction of greenhouse gas emissions (GHG).

For the days of lower irradiation, August $18^{\text {th }} 2016$, the graphs have shown that although the contribution is small, there is still, however, no excess energy generation. The peak hour of demand for this day suffered a slight shift, from 11:00 am to 12:00 am.

For the days of higher irradiation, as can be seen in the graphs of December $5^{\text {th }}, 2016$, there is a considerable change in the demand curve. Between 10:00 am and 4:00 pm the production of energy was above the consumption, and this surplus is turned into credit for later compensation. The demand peak for this day, considering the photovoltaic system, changed from 10:00 am to 08:00 pm, but it remained in the offpeak hours, where energy costs are cheaper.

Regarding the contracted demand, with this study, it was not possible to assert that there would be the possibility of re-contracting a lower demand, suggesting the need of further study. This is due to the fact that the demand of the institution is not directly correlated to climate This means that temperature and solar incidence do not intensely affect routine and use of equipment and, consequently, in the consumption of electric energy.

\section{REFERENCES}

1- ANEEL, National Agency of Electric Energy, Normative Resolution n ${ }^{\circ}$ 482/2012. Available at <http://www2.aneel.gov.br/cedoc/ren2012482.pdf>. Accessed on 26 Jun 2017. 2- INMET, National Institute of Meteorology. Automatic Stations. Available at <http://www.inmet.gov.br/portal/index.php?r=estacoes/estacoesAutomaticas>. Accessed on 26 Jun 2017.

3- Mariano, J.D., Urbanetz Jr, J. Analysis of the demand versus potential curve of photovoltaic generation at UTFPR headquarters, 3rd International Conference on Intelligent Energies. Curitiba-PR. November 16-18, 2016.

4- Mariano, J.D., Analysis of the potential of photovoltaic energy generation to reduce demand peaks and energy contribution in UTFPR buildings in Curitiba. 2017. 194p. Master Thesis (PPGEC). UTFPR, Curitiba-PR, 2017.

5- MME, Ministry of Mines and Energy. Available at <.https: //ben.epe.gov.br/downloads/S\%C3\%ADnn\%20do\%20Relat\%C3\%B3rio\%20Final_2016_Web. pdf $>$. Accessed on 26 Jun 2017. 
6- REN21, "Renewable 2016 - Global Status Report", 2016, Available at <http://www.ren21.net/wp-content/uploads/2017/06/178399_GSR_2017_Full_Report_0621_Opt.pdf>. Accessed on 26 Jun 2017.

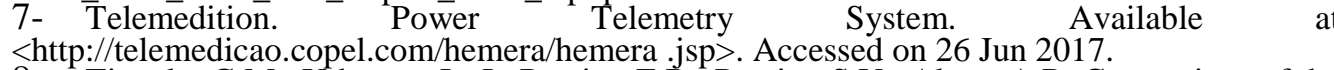
8- Tiepolo, G.M., Urbanetz Jr, J., Pereira, E.B., Pereira, S.V., Alves, A.R. Comparison of the photovoltaic potential of the state of Paraná with other states and Europe - Partial Results. VI Brazilian Congress of Solar Energy, Belo Horizonte-MG. 04 to 07 April 2016.

9- Tiepolo, G.M., Urbanetz Jr, J., Pereira, E.B., Pereira, S.V., Alves, A.R. Potential of electric power generation through grid-connected photovoltaic systems in the state of Paraná Partial Results. VI Brazilian Congress of Solar Energy, Belo Horizonte-MG. 04 to 07 April 2016.

10- Tonin, F.S., Urbanetz Jr, J. Characterization of grid-connected photovoltaic systems SFVCR, 12th International Conference on Industrial Applications. Curitiba-PR. November 20$23,2016$.

11- Urbanetz Jr, J. Solar photovoltaic energy: fundamentals and design of systems. Curitiba, 2012. 